\title{
Applications of IoT in Agriculture
}

\author{
A. Nirmala"1, C. Kumuthini ${ }^{2}$, M. Savithri ${ }^{3}$ \\ ${ }_{1,2}$ Department of Computer Applications, Dr. N. G. P. Arts and Science College, Coimbatore, Tamilnadu, India \\ ${ }^{3}$ Department of Computer Science, Dr. N. G. P. Arts and Science College, Coimbatore, Tamilnadu, India
}

Article Info

Volume 7, Issue 2

Page Number : 105-107

Publication Issue :

March-April-2021

\section{Article History}

Accepted : 20 March 2021

Published : 30 March 2021

\section{ABSTRACT}

Internet of Things technology plays a significant role in agriculture industry. The recent statistics shows that the world population is on the point of reach over 9 billion in the year 2050. The agriculture industry needs to adopt the smart technology to feed this large population. The agriculture Industry depends on innovative ideas to manage growing demand for food. The agriculture operations need smart solutions from IoT by introducing satellite connectivity and expending cellular networks. The entire Agriculture system is improved using IoT based Smart Farming monitoring the field in real-time. Sensors and interconnectivity helps the Internet of Things in Agriculture has not only saved the time of the farmers but has also reduced the extravagant use of resources such as Water and Electricity.

Keywords : IoT, Smart Agriculture, Sensor, Dataanalytics

\section{INTRODUCTION}

In the traditional approach, sensors were introduced in agriculture operations and used to log the data into their attached memory for future process. But the problem is that sensors were not able to get the live data. Later, more advanced sensors are introduced and connected to the cloud through cellular/satellite network for effective utilization. It reads the real time data from the sensors to make effective decision. IoT applications in the agriculture industry help the farmers to make the irrigation process more efficient by monitoring water level. The IoT technology uses the sensors in every step of the farming process. The formers get benefited by adapting IoT are twofold. It helps farmers to decrease their costs and increase yields and also to improve farmer's decision making with accurate data. It implements both connected devices and innovative technologies into agriculture. Smart Farming depends on IoT to increase the productivity in every possible manner. Internet of Things brings huge benefits like efficient use of water, optimization of inputs and many more.

\section{IoT Applications in Agriculture}

In IoT-based smart farming, a system is developed to monitor the crop field by using sensors and to automate the irrigation system. The farmers are able to monitor the field conditions from anywhere. The applications of IoT-based smart farming targets to uplift other growing or common trends in agricultural like organic farming, family farming and enhance highly transparent farming. In terms of environmental issues, IoT-based smart farming provides great benefits in water usage, optimization

Copyright: @ the author(s), publisher and licensee Technoscience Academy. This is an open-access article distributed under the terms of the Creative Commons Attribution Non-Commercial License, which permits unrestricted non-commercial use, distribution, and reproduction in any medium, provided the original work is properly cited 
of inputs and treatments. In this paper, various applications of IoT-based smart farming are presented.

\section{Climate Conditions}

Climate condition is one of the most important components in agriculture industry for quantity and quality of the crop production. IoT solutions help to know the real-time weather conditions. Sensors are placed in the agriculture field to get the data to select the right crops that can grow and sustain in particular weather conditions. The IoT ecosystem detects realtime weather conditions like humidity, rainfall, temperature accurately. The sensors monitor the condition of the crops and the weather surrounding them. An alert will send as soon as founding the disturbing weather.

\section{Precision Farming}

Precision farming helps the formers to analyze the condition of soil and other related parameters to increase the operational efficiency. There are numerous precision farming techniques play a crucial role to increase the efficiency and effectiveness. Precision agriculture/Precision farming makes farming practice more controlled and accurate. In farm management, a key component is the use of IT and various items like sensors, control systems, robotics, autonomous vehicles, automated hardware, variable rate technology, and so on.Precision agriculture is the most eminent applications of IoT in the agricultural sector. The precision agriculture organization CropMetrics focuses on ultra-modern agronomic solutions. The products and services of CropMetrics are VRI optimization, soil moisture probes, virtual optimizer $\mathrm{PRO}$, and so on. Variable Rate Irrigation optimization maximize the productivity on irrigated crop fields through topography or soil variability, improve yields, and increases water use efficiency.

\section{Smart Greenhouse}

IoT in Greenhouses eliminates the human intervention and makes entire process as costeffective and accuracy. IoT enables weather stations for adjusting climate conditions automatically according to the set of instructions that makes smart greenhouses. The greenhouse state is monitored by collecting and transmitting the real-time data by using sensors. The water consumption and greenhouse state can be monitored through emails or SMS alerts.

\section{Data Analytics}

Cloud based data storage and an end-to-end IoT Platform plays an vital role in the smart farming system. The traditional database system does not have enough storage for the data which are collected using sensors. The collected data can be analyzed by using analytics tools and transformed to meaningful information. The data analytics helps to analyze the weather conditions, livestock conditions, and crop conditions. It helps to make better decisions. The farmers can come to know about the status of the crops by getting the data from sensors. The predictive analytics used to make better decisions related to harvesting. The trend analysis used to know upcoming weather conditions and harvesting of crops for farmers. IoT in the Agriculture Industry has helped the farmers to monitor and maintain the quality of crops and fertility of the land and it enhances the product volume and quality.

\section{Agricultural Drones}

Today, agriculture is one of the most important industries to incorporate drones. The agricultural industry can make use of drones to enhance various agricultural practices. The crop health, crop monitoring, planting, crop spraying, and field 
analysis can be analyzed using Ground and Aerial drones. The drones data can be used for for crop health imaging, integrated GIS mapping. It saves time and it would be increase yields. PrecisionHawk is an organization uses drones for gathering valuable data through a series of sensors which are used for imaging, mapping, and surveying of agricultural land. The farmers are entering the details of the field to survey and select an altitude or ground resolution. Then insights of plant health indices, plant counting and yield prediction, plant height measurement, field water ponding mapping, scouting reports, stockpile measuring, chlorophyll measurement and so on can be drawn by using drone's data.

\section{Conclusion}

The IoT based agricultural applications are helping the ranchers and farmers to receive meaningful data. The farmers must understand the importance of IoT market for agriculture by using smart technologies to increase competitiveness and sustainability in their productions. The farmers can meet the demand of the society for food by implementing agricultural IoT solutions in a perfect manner.

\section{REFERENCES}

[1]. Jim Chase: The Evolution of the Internet of Things. White Paper, Texas Instruments, September, 2013.

[2]. Deeksha Jain, P. Venkata Krishna and V. Saritha, "A Study on Internet of Things based Applications", 2012.

[3]. ttp://www.businessinsider.com/internet-ofthings-smart-agriculture-2016-10?IR=T 4Xiaohui Wang and Nannan Liu, "The application of internet of things in agricultural means of production supply chain management", Journal of Chemical and Pharmaceutical Research, 2014, 6(7):2304-2310, ISSN : 0975- 7384,2014.
[4]. Bitponics, http://www.bitponics.com/.

[5]. Botanicalls,http://www.botanicalls.com/.

[6]. S. Navulur, A.S.C.S. Sastry, M. N. Giri Prasad, "Agricultural Management through Wireless Sensors and Internet of Things" International Journal of Electrical and Computer Engineering (IJECE), 2017; 7(6) :3492-3499.

\section{Cite this article as :}

A. Nirmala, C. Kumuthini, M. Savithri, "Applications of IoT in Agriculture", International Journal of Scientific Research in Computer Science, Engineering and Information Technology (IJSRCSEIT), ISSN : 2456-3307, Volume 7 Issue 2, pp. 105-107, MarchApril 2021. Available at

doi : https://doi.org/10.32628/CSEIT217227

Journal URL : https://ijsrcseit.com/CSEIT217227 